\title{
What are the key parameters to produce a high-grade bio-based composite? Application to flax/epoxy UD laminates produced by thermocompression.
}

Thomas Cadu $^{\mathrm{a}, \mathrm{b},{ }^{*}}$; Michael Berges ${ }^{\mathrm{a}, \mathrm{c}, \mathrm{d}}$; Olivier Sicot ${ }^{\mathrm{a}}$; Véronique Person ${ }^{\mathrm{a}}$; Benoit Piezel

${ }^{a}$; Laetitia Van Schoors ${ }^{\text {b }}$ Vincent Placet ${ }^{d}$; Stéphane Corn ${ }^{c}$; Romain Léger ${ }^{c}$; Loïc Divet ${ }^{\text {b; }}$; Patrick lenny ${ }^{\text {c }}$ Stéphane Fontaine ${ }^{\text {a,e }}$

${ }^{a}$ DRIVE EA1859, Univ. Bourgogne Franche-Comté, F-58000 Nevers, France

${ }^{\mathrm{b}}$ Paris-Est University, MAST/CPDM/IFSTTAR 77447 Marne-la-Vallée Cedex 2, France

${ }^{\text {CC}} 2 \mathrm{MA}$, IMT Mines Ales, Univ. Montpellier, Ales, France

dUniv. Bourgogne Franche-Comté, FEMTO-ST Institute, UFC/CNRS/ENSMM/UTBM, Department of

Applied Mechanics, F-25000 Besançon

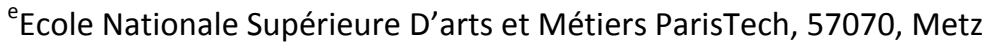

Corresponding author: Thomas Cadu; e-mail address: thomas.cadu@u-bourgogne.fr / olivier.sicot@u-bourgogne.fr Full postal address:

IFSTTAR/CPDM

14-20 Boulevard Newton

Cité Descartes, Champs sur Marne

F-77447 Marne la Vallée Cedex 2

This article has been first published online in Composites Part $\boldsymbol{B}:$ Engineering in May $1^{\text {st }}$, $\underline{2018}$.

https://doi.org/10.1016/j.compositesb.2018.04.059

Abstract: 
The development of composites based on vegetal fibers requires a good control of manufacturing process. The aim of this work is to determine the key parameters to produce high grade flax / epoxy unidirectional laminated composite by thermocompression. So, many processing parameters have been tested and ranked according to their influence on mechanical properties. Since variability can be high for this kind of materials, statistical analyses have been used to determine if properties variations were significant or not. Among all studied parameters, the three which have been identified as first rank influence on mechanical properties are: fibers conditioning, curing pressure and exit plate temperature.

Keywords:
A. Laminates
B. Mechanical properties
E. Cure
E. Thermosetting resin

Flax

\section{Introduction}

These days, structural laminated composite materials are mainly composed of non-renewable fossil resources, such as synthetic fibers and petro-sourced resins. However, the environmental footprints of these composite materials are important. As with for example the European directive 2000/53/EC, regulation encourages the industry to reduce environmental impacts of materials $[1,2]$. Moreover, the public opinion is more and more sensitive to these issues. Since the production of vegetal fibers adapted for this kind of applications needs 5 to 7 times less energy than glass fibers production $[3,4]$, these fibers can be a viable solution to replace synthetic ones. This is why the use of vegetal fibers to replace glass fibers as composite reinforcements in some industrial sectors, such as automotive industries or civil engineering, has emerged during the last decade. Consequently, the flax industry currently develops new production techniques to offer reinforcements with adapted structures to composite materials manufacturing. Indeed, the low density of flax fiber (around $1.5[5,6]$ ) and their 
good mechanical properties can lead to composite materials with specific stiffnesses and strengths comparable to the glass fiber-reinforced ones [7-9]. However, the structure of flax fiber wall is complex and results from the association of multiple constituents (cellulose, hemicellulose, pectin, lignin, waxes, water...) $[10,11]$. This structure can already be perceived as a micro-composite material, in which the pectin plays the role of matrix, reinforced by highly-crystalline cellulose fibrils linked together by hemicellulose, leading to a complex and non-linear tensile behavior of the fiber [8]. In addition, it is challenging to use flax fiber as reinforcements for structural composite materials, because of their low thermal stability and their hydrophilic behavior $[2,8,12,13]$. This affects their in-service and durability properties $[14,15]$.

The performances of a structural bio-based composite material are intimately related to the quality and robustness of its manufacturing process. The parameters of processing influence the microstructure, e.g. the volumetric content of fiber, matrix and void, but also the arrangement of the fibers within the matrix. For a flax fiber reinforced laminated composite, the fibers bring the mechanical resistance and play a decisive role in the hydrophilic properties of the composite. The porosities lead to stress concentrations and lower the mechanical properties [16]. They also increase the moisture uptake of the composite by creating free spaces. As a result, in order to optimize the mechanical properties and the durability of a composite, it is necessary to control its fabrication process to ensure an adapted microstructure. Depending on the various process techniques and parameters found in the literature, unidirectional flax fiber reinforced laminated composites seem to have a range of volumetric fiber content between 26 and $65 \%$, and a volumetric void content between 1.5 and $10 \%$ [15,17-22], leading to tensile properties with a range of Young's modulus between 9 and $33.6 \mathrm{GPa}$ and tensile strength between 133 and $350 \mathrm{MPa}[15,17-22]$.

For the use of thermocompression-like manufacturing processes, the fabrication steps are often the same: (i) preparing and conditioning of the bio-based reinforcements; (ii) curing the composites and reaching specific temperature and pressure conditions to crosslink the resin without degrading the reinforcements; (iii) cooling and (iv) post-curing to complete the cross-linking of the resin. A particular attention must therefore be paid to each of the previous manufacturing step in order to optimize and control both final microstructural and mechanical properties of the produced composites [23]. 
Insofar as the bio-based reinforcements are hydrophilic, their preparation or their conditioning before curing is very important. Vegetal fiber moisture content depends on the history of storage. Some authors highlighted a detrimental effect of moisture content on the fiber/matrix adhesion [18,24]. In parallel, severe drying of vegetal fiber before manufacturing is assumed to lower the mechanical properties of the fiber $[18,25]$. Thus, fluctuations in water content of the reinforcements can induce variability in the final properties of bio-based composites. Since the initial water content of the fiber is a process parameter difficult to control, many authors choose nevertheless to dry fibers before manufacturing their bio-based composite materials [21,26-34]. This choice aims to ensure repeatable mechanical properties of their final composites.

The curing step is assumed to be the most significant one to ensure the fabrication of the best possible bio-based composite. In this step, four interrelated processing parameters are managed: (i) the curing temperature; (ii) the temperature ramp up, (iii) the curing duration and (iv), if required, the applied pressure. The choice of a resin is generally determined according to several criteria. During the process, it is necessary to guarantee the best possible impregnation and a crosslinking temperature which does not damage the reinforcements. It is also necessary to guarantee good synergy between reinforcements and matrix (fiber/matrix adhesion and ability to deform together without interface breakage). Finally, temperatures during future in-service conditions determine the minimum glass transition temperature the resin must reach.

Before crosslinking the resin, a first step consists in optimizing and terminating the impregnation of the reinforcements. In facts, when optimal manufacturing conditions are investigated, it is necessary to fluidize the unpolymerized matrix to ensure a good impregnation. This depends on thermal and rheological properties of the matrix [35]. For thermoset resins, the first part of the curing cycle is generally processed under pressure and at a temperature below the crosslinking temperature of the resin [36-38]. Before polymerization, it is noticeable that thermoplastic resins exhibit higher viscosity, compared to thermosets ones. Generally, fluidizing thermoplastic resins requires higher temperatures and higher pressures are used [36]. This is why thermoset resins appear to suit better the manufacturing of long vegetal fibers thanks to two effects. On one hand, the low viscosity of the uncured resins (about 1 Pa.s at $25^{\circ} \mathrm{C}$ for epoxy [39]) allows a good reinforcement impregnation. On the other hand, the lower the curing temperatures are, the lower the risk of thermal degradation of fiber is. 
Thermoplastic resins often require temperatures above $200^{\circ} \mathrm{C}$ up to more than $400^{\circ} \mathrm{C}$ [40] while some epoxy can crosslink at room temperature and curing temperature are lower than $200^{\circ} \mathrm{C}[39]$.

After impregnation, the temperatures, pressures and durations are set to values allowing the best possible crosslinking of the resin and the best rate of reinforcement as possible. Crosslinking temperatures and durations are specified by resin supplier. Generally, resin data sheets indicate, for several combinations of temperatures and durations, the expected glass transition temperature (Tg) of the polymerized resin. Moreover, the in-service temperatures lead to the choice of resins whose glass transition temperatures are sufficient. In fact, structural bio-based composites dedicated to automotive industry or civil engineering shall undergone in-service temperatures below $90^{\circ} \mathrm{C}$. Resins with $\mathrm{Tg}$ above $100^{\circ} \mathrm{C}$ are thus often the standard. Manufacturers can then choose specific cycles compatible with the nature of the reinforcement and then adapt their fabrication conditions to their facilities and imperatives of time.

There are many examples of polymers used to obtain bio-based composites. For instance, Liang et al. [36] have investigated the influence of processing parameters on the manufacturing of flax/polyamide- 6 by thermo-compression. Their results objectively show that this type of matrix seems to be rather incompatible with flax reinforcements because of the poor mechanical performance of the manufactured composites. This is assumed to be caused by high curing temperature requirements (between 230 and $250^{\circ} \mathrm{C}$ ), that induce severe damages of reinforcements, especially of hemicellulose and lignin [5]. Other authors [41] produced flax/polypropylene composites by thermo-compression at different temperatures $\left(190^{\circ} \mathrm{C}\right.$ and $\left.210^{\circ} \mathrm{C}\right)$. Studied curing durations lasted between 3 and 5 minutes. $200^{\circ} \mathrm{C}$ for 3.5 minutes was considered as the best possible combination to improve mechanical properties (modulus and tensile strength) of their material.

In the case of thermosets, the influence of the curing temperature on the final composite properties has not been studied as much as in case of thermoplastics. This is probably because using thermosets involves lower temperatures and thus less thermal degradation of fiber reinforcements. However, a compromise must be reached between durations and temperatures of the curing cycle. Epoxies or unsaturated polyesters are generally used [38,42-46]. Some authors apply high temperatures $\left(\approx 130^{\circ} \mathrm{C}\right)$ to cure flax/epoxy composite materials by thermo-compression $[38,42,45]$ for a minimal duration $(\approx 2$ h). Others propose to cure flax/epoxy [44,46] or polyester/epoxy [43] at room 
temperature. This induces very long cycle times $(>12 \mathrm{~h})$ that could not be adapted to industrial objectives.

The curing pressure also has significant effects on the quality of the fabricated bio-based composites. In particular, volumetric fiber content and void content can be drastically modified with the pressure. In the case of bio-based composites, the higher the applied pressure is, the higher the reinforcement volumetric ratio and mechanical properties are [47]. It is known that an increase in the volumetric void content leads to a decrease in the mechanical properties [21]. However, by thermocompression, the maximum fiber content for epoxy resin reinforced with unidirectional long vegetal fibers encountered in the literature seems to be $65 \%[15,17-22,34]$. Polypropylene resin reinforced with unbalanced flax fabric reached 57.2 to $59.6 \%$ under 20 bars in the work of Wolfahrt et al. [28]. Shah et al. [48] found a theoretical maximum volumetric fiber content of $60 \%$ for unidirectional composite laminates of jute fibers. Also, increasing pressure induces a decrease in volumetric void content [21] until a certain level of pressure which will be called optimal pressure [49]. Above this optimal pressure, the impregnation if affected, the resin cannot fill the voids of the fully compacted fiber assembly and the void content increases [49] and the fibers are so close together that the stress transfer between fibers and matrix become inefficient [48].

The purpose of the post-curing step is to complete the crosslinking of the resin in order to obtain a composite as stable as possible. The resin suppliers generally indicate that the temperatures and post-curing durations should be identical to those used in crosslinking the resin. Two cases can be found in the literature. Authors who do not take into account the effect of the temperature on fibers, in this case the post-curing can be performed at high temperature $\left(>150^{\circ} \mathrm{C}\right)$ [37], and those who perform post-curing at lower temperature $\left(<70^{\circ} \mathrm{C}\right)$ to minimize fiber degradation caused by water removal $[43,46]$. Different durations are also implemented (from $45 \mathrm{~min}$ to $14 \mathrm{~h}$ ) $[43,46]$.

This state of the art shows that many authors adapt their manufacturing processes to their specific needs. The numerous previous contributions help to illustrate the relations between the final mechanical and microstructural properties of composites and their manufacturing conditions. However, each case is often unique. Depending on the type of reinforcement, resin or manufacturing tools, the published results do not clearly provide direction to help the scientific or industrial community to design a robust fabrication process of bio-based structural composite materials. 
It is then important to consider that the particular nature of the reinforcements must be taken into account to set the manufacturing conditions of bio-based composites. The control and the understanding of the influence of each manufacturing step on the expected properties of the composites must be achieved. This will help to define clear scientific and technological approaches for the manufacture of robust and repeatable bio-based composite laminated structures.

The purpose of this study is to show how the conditioning, curing conditions and post-curing steps impact (i) the quality of the crosslinking of the matrix, (ii) the microstructure of the composites (volumetric void and fiber contents) and (iii) the properties of stiffness and ultimate tensile strength of the composites manufactured.

To achieve this objective, studies were carried out using pure unidirectional flax reinforcements impregnated with a petro-sourced (DGEBA - DiGlycidyl Ether of Bisphenol A) epoxy resin. The chosen process is thermo-compression. Based on the results, the consequences of the choices for each required fabrication step on the final mechanical properties of the composites will be discussed.

\section{Materials and methods}

\subsection{Fibers and matrix}

In this study, pure unidirectional reinforcements FlaxTape ${ }^{\mathrm{TM}} 110$, supplied by the company LINEOC, were used. We measured a density of 1.45 for flax fibers, using Archimedes' principle.

This reinforcement has been selected for its good and reproducible mechanical properties, induced by its industrial production. Moreover, the structure of this reinforcement is purely unidirectional, without sewing yarns. This makes the distribution of the resin easier and reduces induced shear interferences during tensile tests.

The matrix used is a DGEBA epoxy resin (SR 8500 - density 1.17) amine hardener (SZ 8525 density 0.94 ) system produced by Sicomin (C (weight ratio $4: 1$ ). We measured a density of 1.19 for cured matrix, using Archimedes' principle. Epoxy is a widely used thermoset resin, even for bio-based composite laminates. With a hot press process, the supplier recommends to cure composites at $80^{\circ} \mathrm{C}$ for 
1 hour. Under these conditions, the supplier indicates that the resin has a gel time of 8 minutes and reaches the glass transition temperature $(\mathrm{Tg})$ between $104{ }^{\circ} \mathrm{C}$ and $106^{\circ} \mathrm{C}$. To confirm this value, modulated differential scanning calorimetry analyses were carried out on two samples of pure resin thermo-pressed at $80^{\circ} \mathrm{C}$ in the optimal conditions of curing and post-curing determined in the study. A $\operatorname{Tg}$ of $109^{\circ} \mathrm{C}$ was measured, which is compatible with the aimed in-service conditions of this kind of composite materials.

\subsection{Manufacturing process}

The purpose of the manufacturing process is to produce plates in order to study the influence of multiple parameters on the quality and mechanical performance of these composite materials: (i) the conditioning of the reinforcements, (ii) the curing temperature, (iii) the curing pressure, (iv) the cooling speed, (v) the exit temperature, (vi) the post-curing temperature and (vii) the post-curing duration.

\section{Conditioning}

Two batches of fibers were used to produce composite materials: the first batch of reinforcement was not conditioned and stored under ambient conditions. During the storage, a Voltcraft ${ }^{\circledR}$ DL-141TH, humidity and temperature data logger was placed in a flax fibers storage box. Records have been automatically done every 10 minutes. The temperature has been measured at $22 \pm 2$ ${ }^{\circ} \mathrm{C}$ and the humidity at $30 \pm 5 \% \mathrm{RH}$. The second batch of reinforcement was conditioned in a climatic chamber (Vötsch ${ }^{\circledR}$ VC 7100) at $23 \pm 1{ }^{\circ} \mathrm{C}$ and $50 \pm 1 \%$ HR for 7 days before manufacturing.

Impregnation and hand layup

The plies have been manually layed up and impregnated in a specific mold protected by Teflon sheets (figure 1). The draping cycle was as follows: a resin layer is spread on the lower part of the mold. A first ply is positioned in the mold, a resin layer is applied in the center of the flax layer, as it can be seen on figure 1 a). (The resin will be spread under the curing pressure effect as schematized on figure 1 b) and c)). This sequence continues until the stacked number of plies is reached. Finally, the mold is closed and ready to be positioned in the thermo-compression press. This step was performed in $1 \mathrm{~h} \pm 5$ 
mins. This duration is compatible with the pot-life of around 85 minutes at $23^{\circ} \mathrm{C}$ given by the manufacturer Sicomin $\subset$.

\section{Curing and Post-curing}

A Fontijne Grotnes TPC 321 hot press has been used for curing pure unidirectional laminated composites plates. A reference curing cycle is presented in figure 2. First, the temperature increases from $20^{\circ} \mathrm{C}$ to $40^{\circ} \mathrm{C}$ in 10 minutes $\left(2^{\circ} \mathrm{C} / \mathrm{min}\right)$. This step allows to lower the viscosity of the resin and to optimize the impregnation of the reinforcement by the matrix. Pressure (CP) is applied as soon as temperature reaches $40^{\circ} \mathrm{C}$ and maintained throughout the next steps, until the end of the cooling step. Second, the temperature is raised in 15 minutes to the desired curing temperature $(\mathrm{CT})\left(60^{\circ} \mathrm{C}\right.$ or $\left.80^{\circ} \mathrm{C}\right)$ and is maintained for one hour. Third, the mold is cooled from CT to a specified exit temperature ET $\left(20^{\circ} \mathrm{C}, 40^{\circ} \mathrm{C}\right.$ or $60^{\circ} \mathrm{C}$ ) at a defined cooling speed (CS): approximatively $-0.083^{\circ} \mathrm{C} / \mathrm{min}$ for natural cooling (nat), $-1^{\circ} \mathrm{C} / \mathrm{min}$ or $-2^{\circ} \mathrm{C} / \mathrm{min}$. The controlled accelerated cooling speeds $\left(-1\right.$ or $\left.-2^{\circ} \mathrm{C} / \mathrm{min}\right)$ are imposed and controlled thanks to a cold unit (Frigosystem (C) RACA) connected to the thermo-compression press. Finally, a post-curing is conducted within 2 days. Between curing and post-curing the plates were stored in a climatic chamber (Vötsch ${ }^{\circledR}$ VC 7100) at $23 \pm 1{ }^{\circ} \mathrm{C}$ and $50 \pm 1 \% \mathrm{HR}$. The post-curing is carried out in an oven (Memmert UN $450+$ ) for a fixed temperature (PCT) and duration ( $\triangle \mathrm{t} P C)\left(60^{\circ} \mathrm{C}\right.$ or $80^{\circ} \mathrm{C}$ for $1 \mathrm{~h}, 2 \mathrm{~h}$ and $4 \mathrm{~h})$.

Since different parameters have been studied to evaluate their influence on the mechanical properties of the composites, the reference curing cycle has been modified to obtain different materials. This is summarized in Table 1, which is completed by a nomenclature, to designate the plates according to their manufacturing conditions. In the rest of this paper, a plate will be identified with this nomenclature. For instance, a curing cycle with the reference parameters, shown in bold in table 1, will be labelled by the following sequence: $C / 12 P / 3 B / 80 / n a t / 20 / x / x$.

\subsection{Specimen preparation}


Unidirectional tensile specimens were cut with a water lubricated circular saw. The specimens were immediately dried with an absorbent paper after the cutting to avoid water sorption. According to geometry 4 from ISO 527 standard, their dimensions are $250 \mathrm{~mm}$ long, $25 \mathrm{~mm}$ wide. The 12 plies specimens have a thickness between 1.7 and $1.8 \mathrm{~mm}$ under 3 bars. The 20 plies specimens have a thickness between 2.6 and $3.5 \mathrm{~mm}$ depending on the applied pressure (the higher the pressure is, the lower the thickness is). Before testing, the specimens have been conditioned at $23 \pm 1{ }^{\circ} \mathrm{C}$ and $50 \pm 1 \% \mathrm{HR}$ for 7 days minimum in a climatic chamber (Vötsch ${ }^{\circledR}$ VC 7100). The specimens have not been equipped with tabs.

\subsection{Determination of volumetric composition}

Volumetric composition of the composite was determined by weighing method inspired from ASTM D 3171 - 99. For each produced plate, one specimen, described above, was weighed with a Kern PRS balance ( $0.1 \mathrm{~g}$ precision), its width and thickness were measured with a numeric caliper $(0.01 \mathrm{~mm}$ precision) and its length was measured with a ruler $(0.5 \mathrm{~mm}$ precision). The determination of the resin and the fibers densities is explained in the physicochemical characterization section. Then, the volumetric fiber, resin and void contents were calculated with the following equations:

$$
\begin{aligned}
& W f=A w \times N \times L \times l \\
& V f=\frac{W f}{\rho f \times V c} \times 100 \\
& V r=\frac{W c-W f}{\rho r \times V c} \times 100 \\
& V p=100-V f-V r
\end{aligned}
$$

with Wf: fibers weight (g); Aw: areal weight of the fabric $\left(\mathrm{g} \cdot \mathrm{m}^{-2}\right) ; \mathrm{N}$ : number of plies; L: length of the specimen (m); I: width of the specimen (m); Vf: volumetric fiber content (\%); pf: fiber density $\left(\mathrm{g} / \mathrm{m}^{3}\right)$; Vc: composite volume $\left(\mathrm{m}^{3}\right)$; $\mathrm{Vr}$ : volumetric resin content (\%) ; Wc: composite weight (g); pr: resin density 
$\left(\mathrm{g} / \mathrm{m}^{3}\right)$; Vp: volumetric void content (\%). This determination of volumetric composition is sensitive to small deviations of specimen's dimensions' measurements and to the reinforcement density dispersion. Then, samples have been measured precisely and the uncertainty of measurements has been taken into account in calculations. Moreover the stack of 20 plies averaged the variation of the reinforcement density along the roller width.

\subsection{Microscopic observations}

Untested $20 \times 20 \mathrm{~mm}$ specimens were cut with a water lubricated circular saw then dried in absorbent paper. They were coated with EpoFix (C) resin from Struers and conditioned at $23 \pm 1{ }^{\circ} \mathrm{C}$ and $50 \pm 1 \%$ HR for 7 days before their observation under a Nikon Eclipse LV150 optic microscope. These observations were conducted to inspect the composite microstructure, especially the presence of porosities, for different manufacturing pressures.

\subsection{Mechanical testing}

Tensile tests were conducted on unidirectional $0^{\circ}$ samples according to the ISO 527-4 standard on a MTS Criterion C45, equipped with a $100 \mathrm{kN}$ load cell and a $50 \mathrm{~mm}$ gauge length extensometer. Test speed was set at $1 \mathrm{~mm} \cdot \mathrm{min}^{-1}$. For each plate, 4 specimens were tested. According to the ISO 527-4 standard, the Young's modulus for unidirectional fiber-reinforced composite is measured in a strain range of $0.05 \%$ to $0.25 \%$. This strain range is well-suited to synthetic fiber-reinforced composites but not to flax fiber-reinforced composites. Indeed, the tensile curve for a flax fiber-reinforced composite is not linear $[15,50]$. As presented on figure 3 , this nonlinearity results in the appearance of an inflection on the stress-strain curve, often in the strain range of $0.05 \%$ to $0.25 \%$. If the standard is used to calculate the tensile modulus of our unidirectional composites, it will be thus under-estimated. For this reason, two modules E1 and E2 are defined in the dotted areas on the figure 3, respectively the squares and the circles ones. The strain range of these areas depends on the position of the inflexion point on the curve, which differs with the processing parameters variations. 


\subsection{Physicochemical characterization}

\section{Modulated Differential Scanning Calorimetry (MDSC) analyses}

MDSC analyses have been performed with a TA Instrument DSC 250 differential scanning calorimeter. MDSC has been preferred to classic DSC because it allows separating reversible and nonreversible phenomena. This enables to measure the glass transition temperature ( $\mathrm{Tg}$ ) of the material despite the thermal phenomena due to fibers which can disrupt the signal. For each analysis thermal cycle has been carried out from $25^{\circ} \mathrm{C}$ to $130^{\circ} \mathrm{C}$ and the $\mathrm{Tg}$ has been determined using the reversible signal. For each plate, analyses have been performed on 2 samples.

\section{Thermo-gravimetric analyses}

In order to estimate water content of the fibers, depending on their storage conditions before manufacturing process, thermo-gravimetric analyses have been carried on flax fibers samples using a NETZSCH STA 449 F1. Based on this study [51], isothermal analyses have been performed on conditioned and non-conditioned fibers. Each were carried out at $105^{\circ} \mathrm{C}$ for $14 \mathrm{~h}$ then $150^{\circ} \mathrm{C}$ for $5 \mathrm{~h}$ in one run.

\section{Density measurements}

Densities of fibers, resin and composites, have been measured using Archimedes' principle. Each sample has been successively weighed in air and in dodecane solution. Dodecane has been chosen to avoid solvent sorption by the fibers. Density of the sample (d) has been calculated using the equation 5. For each plate, 5 samples have been weighed.

$$
d=\frac{m_{\text {air }} \times d_{\text {dod }}-m_{\text {dod }} \times d_{\text {air }}}{m_{\text {air }}-m_{\text {dod }}}
$$

with $\mathrm{m}_{\text {air }}$ : mass of the sample measured in the air $(\mathrm{g}) ; \mathrm{m}_{\mathrm{dod}}$ : mass of the sample measured in dodecane (g); $d_{\text {air }}$ : density of the air $\left(6 \cdot 10^{-4}\right.$ g.m $\mathrm{m}^{3}$ at $\left.21^{\circ} \mathrm{C}\right) ; \mathrm{d}_{\text {dod }}$ : density of dodecane $\left(0.7487 \mathrm{~g} \cdot \mathrm{m}^{3}\right.$ at $\left.21^{\circ} \mathrm{C}\right)$. 


\section{Results}

In this section, results are presented in order to classify the influence of processing steps on micro-structural properties (volumetric fiber content, volumetric void content, glass transition temperature) and mechanical ones (both E1, E2 moduli and ultimate tensile strength $\sigma_{\max }$ ) of fabricated laminates. Before discussing these results, a statistic variance test (ANOVA) has been implemented to ensure that the variation observed between two groups of specimen is statistically significant. The significance of the variation between the average values will be noted $\mathrm{S}$ and is calculated with $\mathrm{S}=\frac{F}{F_{\text {crit }}}$. F is calculated with the intergroup variance (variance considering all specimens) divided by the intragroup variance (mean value of the variances of the two groups of specimens) and $F_{c r i t}$ is determined on a $95 \%$ safety Snedecor F-table. F and $F_{\text {crit }}$ values are automatically calculated with Excel's ANOVA function. If $S>1$, the null hypothesis of the ANOVA test is invalid, which means that the specimens do not belong to a single population. In other terms, if $S>1$, observed variations between averages of two groups can be assumed as significant.

\section{Structural properties (volumetric fiber content, volumetric void content and glass transition}

\section{temperature):}

The most influential manufacturing parameter on the microstructure of laminates is the pressure. On a 20 ply-laminate, the volumetric fiber content is around $38 \%$ for 1 bar, $45 \%$ for 3 bars and $51 \%$ for 5 bars. The volumetric void content is also impacted by the pressure; contents of around $2.4 \%, 2.5 \%$ and $3.1 \%$ were measured respectively for 1,3 and 5 bars. By TGA analysis water content has been measured between 5 and $7 \%$ in mass for non-conditioning fibers and to $7 \%$ for conditioned fibers which is in accordance with the literature [51]. The glass transition temperature of each composite has been measured and compared with the one given by the manufacturer for pure matrix cured 2 hours at $80^{\circ} \mathrm{C}\left(106^{\circ} \mathrm{C}\right)$. In all cases it was slightly upper. The matrix is thus assumed to be well crosslinked.

\section{Mechanical properties (E1, E2 and $\left.\sigma_{\max }\right)$}

In the following observations, the process parameters were classified in terms of rank of influence on the studied properties of the composites (moduli and ultimate tensile strength). Ranks 1 
and 2 correspond respectively to major and minor influences on the properties of the composites. An influence is considered to be major when the observed variation on the average values of the studied properties of the composites is greater than $15 \%$ with $S>1$. A minor influence corresponds to observed property variations between $10 \%$ and $15 \%$ with $S>1$. The $3^{\text {rd }}$ rank corresponds to a trend of mean value evolution (average variation $>10 \%$ and with $0.5<\mathrm{S}<1$ ) with a low significance. The letter $\mathrm{X}$ denotes a negligible evolution. The following table ( $\operatorname{Tab} 2$ ) sums up the criteria used to classify the parameters.

Influence of the processing parameters on E1:

The figure 4 shows that the different processing parameters have different effects on E1. Some processing parameters have a negligible influence: the curing temperature, the cooling speed and the post-curing temperature induce less than $10 \%$ change in the E1 value and S lower than 0.2. However, even if the post-curing duration has no significant effect on the mean value of E1, a clear reduction of the standard deviation was observed for durations of $2 \mathrm{~h}$ and $4 \mathrm{~h}$ ( $64 \%$ reduction of the standard deviation from no post-curing to $2 \mathrm{~h}$ post-curing duration). The specimens tested to determine the influence of post-curing duration have been randomly selected on the plates. Moreover, the specimens with post-curing of $1 \mathrm{~h}$ have not been all tested then the ones with $2 \mathrm{~h}$, etc. i.e. The order in which we tested these samples was also random. This tends to indicate that the reduction of the dispersion of the results is linked to the duration of the post-curing more than it was in the selection or in test conditions of the samples. To produce reproducible laminates, this parameter is thus important and it will be classified as a $2^{\text {nd }}$ rank parameter.

On the other hand, the fiber conditioning, the pressure and the exit temperature have significant consequences. For 12 ply-laminates, using conditioned reinforcements leads to a $12 \%$ increase of $\mathrm{E} 1$ mean value $(S=1.20)$. Conditioning of fiber is then a $2^{\text {nd }}$ rank parameter.

Moreover, as a consequence of the increase in the reinforcement rate, increasing curing pressure induces $16 \%$ and $23 \%$ increase in $\mathrm{E} 1$ mean value when the pressure is increased from respectively 1 bar to 3 bar and from 1 bar to 5 bars $(S=1.37$ between 1 and 3 bar and $S=4.55$ for 1 to 5). Finally, a $21 \%$ increase of E1 mean value is observed when the composite is unmolded at room 
temperature, in comparison with an outlet at $60^{\circ} \mathrm{C}(\mathrm{S}=2.04)$. Thus, pressure and exit temperature will be classified as $1^{\text {st }}$ rank parameters.

Influence of the processing parameters on the E2 modulus:

As with E1, the curing temperature and the cooling speed have no significant influence of the E2 modulus, with less than $10 \%$ variation of the mean value and S lower than 0.2 , as shown in Figure 5. As observed for the E1 modulus, the post-curing duration has no significant influence (less than 6\%) on E2 modulus. However, a clear reduction of the standard deviation is observed for $2 \mathrm{~h}$ and $4 \mathrm{~h}$ of postcuring ( $32 \%$ reduction of the standard deviation from no post-curing to $2 \mathrm{~h}$ post-curing duration). As indicated for E1, specimens were randomly selected and tested, so to ensure reproducible laminate fabrication, the post-curing duration has to be considered as a $2^{\text {nd }}$ rank parameter on E2.

Contrary to the observations made on the module E1, a rank 3 influence can be observed concerning the post-curing temperature, with a $13 \%$ increase in $\mathrm{E} 2$ between $60^{\circ} \mathrm{C}$ and $80^{\circ} \mathrm{C}(\mathrm{S}=0.54)$.

As seen in the case of E1, the fiber conditioning, the pressure (1 to 3 bars) and the exit temperature respectively increase E2 of $+20-25 \%(S=5.64-2.68),+20 \%(S=1.59)$ and $+28 \%(S=3.72)$. These process parameters are then classified as $1^{\text {st }}$ rank ones.

Influence of processing parameters on the ultimate tensile strength $\sigma_{\text {max }}$ :

The fibers conditioning, the curing temperature and the post-curing temperature have negligible impacts (in the range of studied parameters) on the ultimate tensile strength, with less than $10 \%$ variations and $\mathrm{S}$ lower than 0.6 , as shown in Figure 6 . The post-curing duration still has the same effect as for the E1 and E2 moduli: there is no significant change in the mean value but a clear decrease of the standard deviation for durations of $2 \mathrm{~h}$ and $4 \mathrm{~h}$ is observed ( $52 \%$ reduction of the standard deviation from no post-curing to $2 \mathrm{~h}$ post-curing duration). As indicated for E1 and E2, specimens were randomly selected and tested. To ensure reproducible laminate fabrication, the post-curing duration effect on $\sigma_{\max }$ can also be considered important and will also be classed as a $2^{\text {nd }}$ rank parameter.

The exit temperature has lower influence on $\sigma_{\max }$ than on moduli but a trend can still be observed with a $16 \%$ increase of the mean value when the composite is unmolded at room temperature, in comparison with an outlet at $60^{\circ} \mathrm{C}(\mathrm{S}=0.68)$. The increase of the curing temperature 
from $60^{\circ} \mathrm{C}$ to $80^{\circ} \mathrm{C}$ induces a $12 \%$ increase of $\sigma_{\max }$ mean value but regarding the ANOVA test this variation is considered as non-significant $(S=0.15)$.

Cooling speed has a $2^{\text {nd }}$ rank influence on $\sigma_{\max }$. Hence, reducing cooling speed from $2^{\circ} \mathrm{C} / \mathrm{min}$ to natural cooling $\left(0.083^{\circ} \mathrm{C} / \mathrm{min}\right)$ induces a $14 \%$ increase in $\sigma_{\max }(S=2.50)$.

The pressure still has a major influence on $\sigma_{\max }$ in relation with the evolution of the volumetric fiber content, with an increase of $18 \%$ between 1 bar and 3 bars $(S=1.86)$ and $22 \%$ between 1 bar and 5 bars. The pressure will be classified as $1^{\text {st }}$ rank parameter.

The following table (Tab 3) sums up the previously illustrated results in terms of process parameters influence rank on fabricated laminates final properties.

The most important parameters to achieve good mechanical properties have been identified. The pressure applied during the process determines the microstructure and has a paramount effect on the mechanical properties. The exit temperature has an important effect on both E1 and E2 moduli. Also, both moduli are impacted by the conditioning, but even though E1 modification is non negligible, E2 modification is more significant. To ensure a repeatable fabrication, the post-curing duration is the most important parameter. Although these parameters influence has been identified, the phenomenon leading to the modification of the properties are numerous and complex. The goal of the following section is to discuss the link between process parameters and induced mechanical properties.

\section{Discussion}

The figure 7 sums up the tested parameters, their influence on the composites mechanical properties and the optimal process cycle, in the range of studied parameters. Our goals were to optimize mechanical properties and reduce process duration. This study underlined that, at least, four manufacturing parameters have a major impact on composites mechanical properties. Nevertheless, we did not study some parameters such as the impregnation method, the temperature ramp up and the curing duration. 
The pressure is a rank 1 parameter for both moduli and the ultimate tensile strength.

Microscopic observations of our composites specimens (Figure 8) confirm that the volumetric fiber content increases when the pressure increases from 1 to 3 bars and from 3 bars to 5 bars, even though mechanical properties only improve from 1 to 3 bars. Moreover, the volumetric void content, stable from 1 to 3 bars, slightly increases from 3 to 5 bars, which indicates that the optimal pressure was exceeded at 5 bars. This optimal pressure is most likely to be between 3 and 5 bars.

The exit temperature is a rank 1 parameter for both moduli. It could be related to the freeze of the epoxy network organization. This would lead to residual stresses that could affect the mechanical properties.

The conditioning of the fibers is a rank 1 parameter for E2 modulus and a rank 2 parameter for E1 modulus. The significant effect on both moduli we observed is in agreement with literature, in which it was found that moisture content strongly affects mechanical properties of flax fiber [51]. However we did not determined the optimal conditioning parameters in this study.

The post-curing duration is a rank 2 parameter for both moduli and the ultimate tensile strength. Our results show that a sufficient post-curing duration homogenizes the mechanical properties. Post-curing has generally two effects: completing the reticulation of the resin and releasing the internal stresses. The glass transition temperature $\left(110 \pm 1.4^{\circ} \mathrm{C}\right)$ is stable and post-curing temperature does not have a significant effect on it, which means that we can exclude the effect on the reticulation. Although, internal residual stresses can modify the damage and failure mechanisms leading to a dispersion of the results. Thus, this would be consistent with the observed evolution of the properties.

Based on the results of this study, some recommendations can be made to obtain flax-epoxy composites with good properties. A picture and a macroscopic observation of the composite fabricated with our recommended manufacturing process is presented on figure 9.

First, matrix has to be chosen to crosslink at compatible temperatures. Temperatures around $80^{\circ} \mathrm{C}$ seem to be well adapted. Indeed, they reduce the risk of potential degradation of fiber and enable the use of matrix that can achieve a good cross-linking in a relatively short manufacturing time. Then, it is important to control the moisture content of fiber to ensure a reproducible manufacturing process. 
Conditioning fibers before the production of composites looks the most suitable for vegetal fibers since it improves composites moduli. The optimal conditioning parameters have to be determined, depending on fiber and matrix natures. Also, among the parameters we studied, the pressure was the one with the greatest influence on composites properties. Thus, it is important to be careful about the pressure used. It was shown that an optimal pressure exists. In our case, the pressure was set to 3 bars but the optimal value is between 3 and 5 bars. The optimal value has to be determined for each reinforcement, because it depends on its structure and weight. Moreover, the end of the curing cycle should not be neglected since the exit temperature has a major impact on both moduli. It is recommended to use a controlled cooling speed $\left(-1\right.$ or $-2^{\circ} \mathrm{C} / \mathrm{min}$ ) down to $20^{\circ} \mathrm{C}$. Even though the "natural" cooling in the thermocompression press down to $20^{\circ} \mathrm{C}$ gave the best results in terms of ultimate tensile strength, it is much longer and may not be the most suitable choice for industrial production. Finally, in order to homogenize and reduce standard variation of composite mechanical properties, it is useful to carry out a post-curing step. Indeed the dispersion of the properties in bio-based composites is one obstacle to the use at a larger scale of this kind of materials in the industry. Its duration has to be determined to suit the acceptable standard deviation for the considered usage. However, we observed that the dispersion is reduced down to a minimum (after $2 \mathrm{~h}$ in our case) and constant afterward. To confirm and validate the relevance of this step it should be interesting to quantify its impact on global environmental footprint through complete life cycle assessment.

\section{Conclusion}

This study aimed at developing and optimizing a reliable manufacturing process for laminated composites using flax fibers. The influence of many process parameters has been studied. These parameters have been classified according to their impacts on mechanical properties, allowing the determination of the most critical ones. Indeed, the fiber conditioning, the pressure, the cooling speed, the exit temperature and the post-curing duration proved to be the most decisive parameters in terms of mechanical properties. Thus, this paper gives some keys to obtain a good quality vegetal fibers composite and the method used can be adapted for different fibers or matrix. 
To complete this study, the influence of some other parameters could be investigated, such as the temperature ramp up and the curing duration that were not studied here. Moreover, on the basis of this study, models should be developed to link processes steps and properties in order to generalize this approach to composites made with different vegetal fibers.

Acknowledgements

This project is supported by the Bourgogne Franche-Comté region.

Declaration of interest: none

\section{References}

[1] Shah DU. Developing plant fibre composites for structural applications by optimising composite parameters: a critical review. J Mater Sci 2013;48:6083-107. doi:10.1007/s10853-013-7458-7.

[2] John MJ, Thomas S. Biofibres and biocomposites. Carbohydr Polym 2008;71:343-64. doi:10.1016/j.carbpol.2007.05.040.

[3] Le Duigou A, Davies P, Baley C. Environmental Impact Analysis of the Production of Flax Fibres to be Used as Composite Material Reinforcement. J Biobased Mater Bioenergy 2011;5:153-65. doi:10.1166/jbmb.2011.1116.

[4] Brosius D. Natural Fiber Composites Slowly Take Root. Compos Technol 2006;12:32-7.

[5] Baley C. Analysis of the flax fibres tensile behaviour and analysis of the tensile stiffness increase. Compos Part A Appl Sci Manuf 2002;33:939-48. doi:10.1016/S1359-835X(02)00040-4.

[6] Amiri A, Triplett Z, Moreira A, Brezinka N, Alcock M, Ulven CA. Standard density measurement method development for flax fiber. Ind Crop Prod 2017;96:196-202. doi:10.1016/j.indcrop.2016.11.060.

[7] Verpoest I. A general introduction to composites, highlighting the advantages of flax and hemp composites. Reux Verpoest n.d.;2012:15-37.

[8] Charlet K. Contribution à l'étude de composites unidirectionnels renforcés par des fibres de lin : 
relation entre la microstructure de la fibre et ses propriétés mécaniques. Université de Caen / Basse-Normandie, 2008. French. (tel-01133091).

[9] Coroller G, Lefeuvre A, Le Duigou A, Bourmaud A, Ausias G, Gaudry T, et al. Effect of flax fibres individualisation on tensile failure of flax/epoxy unidirectional composite. Compos Part A Appl Sci Manuf 2013;51:62-70. doi:10.1016/j.compositesa.2013.03.018.

[10] Baley C. Fibres naturelles de renfort pour matériaux composites. Tech L'ingénieur 2013;AM 5 130:1-17.

[11] Morvan C, Andème-Onzighi C, Girault R, Himmelsbach DS, Driouich A, Akin DE. Building flax fibres: more than one brick in the walls. Plant Physiol Biochem 2003;41:935-44. doi:10.1016/j.plaphy.2003.07.001.

[12] Alix S, Philippe E, Bessadok A, Lebrun L, Morvan C, Marais S. Effect of chemical treatments on water sorption and mechanical properties of flax fibres. Bioresour Technol 2009;100:4742-9. doi:10.1016/j.biortech.2009.04.067.

[13] Van de Velde K, Baetens E. Thermal and Mechanical Properties of Flax Fibres as Potential Composite Reinforcement. Macromol Mater Eng 2001;286:342-9. doi:10.1002/14392054(20010601)286:6<342::AID-MAME342>3.0.CO;2-P.

[14] Hearle JWS. The fine structure of fibers and crystalline polymers. III. Interpretation of the mechanical properties of fibers. J Appl Polym Sci 1963;7:1207-23. doi:10.1002/app.1963.070070403.

[15] Berges M, Léger R, Placet V, Person V, Corn S, Gabrion X, et al. Influence of moisture uptake on the static , cyclic and dynamic behaviour of unidirectional flax fibre-reinforced epoxy laminates. Compos Part A 2016;88:165-77. doi:10.1016/j.compositesa.2016.05.029.

[16] Liu L, Zhang B, Wang D, Wu Z. Effects of the cure cycles on void content and mechanical properties of composite laminates. Compos Struct 2006;73:303-9.

[17] Van de Weyenberg I, Ivens J, De Coster A, Kino B, Baetens E, Verpoest I. Influence of processing and chemical treatment of flax fibres on their composites. Compos Sci Technol 2003;63:1241-6. doi:10.1016/S0266-3538(03)00093-9.

[18] Masseteau B, Michaud F, Irle M, Roy A, Alise G. An evaluation of the effects of moisture content on the modulus of elasticity of a unidirectional flax fiber composite. Compos Part A Appl Sci 
Manuf 2014;60:32-7. doi:10.1016/j.compositesa.2014.01.011.

[19] Scida D, Assarar M, Poilâne C, Ayad R. Influence of hygrothermal ageing on the damage mechanisms of flax-fibre reinforced epoxy composite. Compos Part B Eng 2013;48:51-8. doi:10.1016/j.compositesb.2012.12.010.

[20] Li Y, Xue B. Hydrothermal ageing mechanisms of unidirectional flax fabric reinforced epoxy composites. Polym Degrad Stab 2016;126:144-58. doi:10.1016/j.polymdegradstab.2016.02.004.

[21] Li Y, Li Q, Ma H. The voids formation mechanisms and their effects on the mechanical properties of flax fiber reinforced epoxy composites. Compos Part A Appl Sci Manuf 2015;72:40-8. doi:10.1016/j.compositesa.2015.01.029.

[22] Martin N, Davies P, Baley C. Comparison of the properties of scutched flax and flax tow for composite material reinforcement. Ind Crops Prod 2014;61:284-92.

doi:10.1016/j.indcrop.2014.07.015.

[23] Van de Velde K, Kiekens P. Thermoplastic pultrusion of natural fibre reinforced composites. Compos Struct 2001;54:355-60.

[24] Bledzki AK, Mamun AA, Lucka-Gabor M, Gutowski VS. The effects of acetylation on properties of flax fibre and its polypropylene composites. Express Polym Lett 2008;2:413-22. doi:10.3144/expresspolymlett.2008.50.

[25] le Duigou A, Bourmaud A, Balnois E, Davies P, Baley C. Improving the interfacial properties between flax fibres and PLLA by a water fibre treatment and drying cycle. Ind Crops Prod 2012;39:31-9. doi:10.1016/j.indcrop.2012.02.001.

[26] Masania K, Woigk W, Rion J, Dransfeld C, Materials C. Effect of Fibre Volume Content on the Mechanical Performance of Natural Fibre Reinforced Thermoplastic. ECCM17 2016:26-30.

[27] Monti A, El Mahi A, Jendli Z, Guillaumat L. Mechanical behaviour and damage mechanisms analysis of a flax-fibre reinforced composite by acoustic emission. Compos Part A Appl Sci Manuf 2016;90:100-10. doi:10.1016/j.compositesa.2016.07.002.

[28] Wolfahrt M, Sinic J, Pichler S, Wuzella G, Competence P, Competence P, et al. Effect of moisture absorption on selected mechanical properties of natural fiber composites based on woven flax fibers and polypropylene. ECCM17 2016:26-30.

[29] Le Duigou A, Bourmaud A, Davies P, Baley C. Long term immersion in natural seawater of 
Flax/PLA biocomposite. Ocean Eng 2014;90:140-8. doi:10.1016/j.oceaneng.2014.07.021.

[30] Memon A, Nakai A. Fabrication and Mechanical Properties of Jute Spun Yarn/PLA Unidirection Composite by Compression Molding. Energy Procedia 2013;34:830-8.

doi:10.1016/j.egypro.2013.06.819.

[31] Madsen B, Aslan M, Lilholt H. Fractographic observations of the microstructural characteristics of flax fibre composites. Compos Sci Technol 2016;123:151-62. doi:10.1016/j.compscitech.2015.12.003.

[32] Kim H, Seo D. Effect of water absorption fatigue on mechanical properties of sisal textilereinforced composites. Int J Fatigue 2006;28:1307-14. doi:10.1016/j.ijfatigue.2006.02.018.

[33] Gassan J, Bledzki AK. Effect of cyclic moisture absorption desorption on the mechanical properties of silanized jute-epoxy composites. Polym Compos 1999;20:604-11. doi:10.1002/pc.10383.

[34] Newman RH. Auto-accelerative water damage in an epoxy composite reinforced with plainweave flax fabric. Compos Part A Appl Sci Manuf 2009;40:1615-20. doi:10.1016/j.compositesa.2009.07.010.

[35] Ho M, Wang H, Lee J, Ho C, Lau K, Leng J, et al. Critical factors on manufacturing processes of natural fibre composites. Compos Part B Eng 2012;43:3549-62.

doi:10.1016/j.compositesb.2011.10.001.

[36] Liang S, Nouri H, Lafranche E. Thermo-compression forming of flax fibre-reinforced polyamide 6 composites: influence of the fibre thermal degradation on mechanical properties. J Mater Sci 2015;50:7660-72. doi:10.1007/s10853-015-9330-4.

[37] Le Guen M-J, Newman RH, Fernyhough A, Staiger MP. Tailoring the vibration damping behaviour of flax fibre-reinforced epoxy composite laminates via polyol additions. Compos Part A Appl Sci Manuf 2014;67:37-43. doi:10.1016/j.compositesa.2014.08.018.

[38] Poilâne C, Vivet A, Momayez L, Doudou B Ben, Ayachi M, Chen J. Propriétés mécaniques de préimprégnés lin/époxyde. JNC 16, Toulouse, France: AMAC; 2009, p. 10.

[39] Penn LS, Wang H. Epoxy Resins. In: Peters ST, editor. Handb. Compos. second edi, Springer US; 1998, p. 48-74.

[40] Whitten WK. Handbook of Composites. vol. 32. Boston, MA: Springer US; 1998. 
doi:10.1007/978-1-4615-6389-1.

[41] Van de Velde K, Kiekens P. Effect of material and process parameters on the mechanical properties of unidirectional and multidirectional flax/polypropylene composites. Compos Struct 2003;62:443-8. doi:10.1016/j.compstruct.2003.09.018.

[42] George J, Ivens J, Verpoest I. Mechanical properties of flax fibre reinforced epoxy composites. Die Angew Makromol Chemie 1999;272:41-5. doi:10.1002/(SICI)15229505(19991201)272:1<41::AID-APMC41>3.0.CO;2-X.

[43] Hughes M, Carpenter J, Hill C. Deformation and fracture behaviour of flax fibre reinforced thermosetting polymer matrix composites. J Mater Sci 2007;42:2499-511. doi:10.1007/s10853006-1027-2.

[44] Saidane EH, Scida D, Assarar M, Ayad R. Assessment of 3D moisture diffusion parameters on flax/epoxy composites. Compos Part A Appl Sci Manuf 2016;80:53-60. doi:10.1016/j.compositesa.2015.10.008.

[45] Duc F, Bourban PE, Plummer CJG, Månson J-AE. Damping of thermoset and thermoplastic flax fibre composites. Compos Part A Appl Sci Manuf 2014;64:115-23. doi:10.1016/j.compositesa.2014.04.016.

[46] Le Duigou A, Davies P, Baley C. Exploring durability of interfaces in flax fibre/epoxy microcomposites. Compos Part A Appl Sci Manuf 2013;48:121-8.

doi:10.1016/j.compositesa.2013.01.010.

[47] Gning PB, Liang S, Guillaumat L, Pui WJ. Influence of process and test parameters on the mechanical properties of flax/epoxy composites using response surface methodology. J Mater Sci 2011;46:6801-11. doi:10.1007/s10853-011-5639-9.

[48] Shah DU, Schubel PJ, Licence P, Clifford MJ. Determining the minimum, critical and maximum fibre content for twisted yarn reinforced plant fibre composites. Compos Sci Technol 2012;72:1909-17. doi:10.1016/j.compscitech.2012.08.005.

[49] Liholt H, Madsen B. Volumetric composition in composites and historical data. Proc 18th Ris $\varnothing$ Int Symp Mater Sci 2013;34:279-94.

[50] Poilâne C, Cherif ZE, Richard F, Vivet A, Ben Doudou B, Chen J. Polymer reinforced by flax fibres as a viscoelastoplastic material. Compos Struct 2014;112:100-12. 
doi:10.1016/j.compstruct.2014.01.043.

[51] Baley C, Le Duigou A, Bourmaud A, Davies P. Influence of drying on the mechanical behaviour of flax fibres and their unidirectional composites. Compos Part A Appl Sci Manuf 2012;43:1226-33. doi:10.1016/j.compositesa.2012.03.005. 


\section{Figure captions:}

Figure 1: Impregnation of a ply a), spread of the resin under curing pressure effect b), resin distributed over all the plate c).

Figure 2: curing cycle of composites

Figure 3: Tensile curve of an UD flax fiber-reinforced composite on the $0 \%$ to $0.4 \%$ strain range with $E_{1}$ determined on squares area and $\mathrm{E}_{2}$ determined on circles area

Figure 4: Influence of the processing parameters on the E1 modulus (GPa) with: $1^{\text {st }}$ rank influence in black, $2^{\text {nd }}$ rank influence in dark grey, $3^{\text {rd }}$ rank influence in light grey and negligible influence in white. Influence of: $\mathrm{NC}-\mathrm{C}$ ) fibers conditioning, P) pressure, $\mathrm{CT}$ ) curing temperature, $\mathrm{CS}$ ) cooling speed, ET) exit temperature, $\mathrm{PCT}$ ) post-curing temperature and $\triangle \mathrm{t} \mathrm{PC}$ ) post-curing duration.

Figure 5: Influence of the fabrication parameters on the E2 modulus (GPa) with: $1^{\text {st }}$ rank influence in black, $2^{\text {nd }}$ rank influence in dark grey, $3^{\text {rd }}$ rank influence in light grey and negligible influence in white. Influence of: $\mathrm{NC}-\mathrm{C}$ ) fibers conditioning, P) pressure, $\mathrm{CT}$ ) curing temperature, $\mathrm{CS}$ ) cooling speed, ET) exit temperature, $\mathrm{PCT}$ ) post-curing temperature and $\Delta \mathrm{t} \mathrm{PC}$ ) post-curing duration.

Figure 6: Influence of the fabrication parameters on the ultimate tensile strength (MPa) with: $1^{\text {st }}$ rank influence in black, $2^{\text {nd }}$ rank influence in dark grey, $3^{\text {rd }}$ rank influence in light grey and negligible influence in white. Influence of: $\mathrm{NC}-\mathrm{C}$ ) fibers conditioning, P) pressure, CT) curing temperature, CS) cooling speed, ET) exit temperature, $\mathrm{PCT}$ ) post-curing temperature and $\Delta \mathrm{t} \mathrm{PC}$ ) post-curing duration.

Figure 7: Flow chart of the manufacturing process and impacts of the different parameters on mechanical properties 
Figure 8: Microscopic observations of the composites fabricated under: (a) 1 bar; (b) 3 bars; (c) 5 bars (in circles: fibers; in squares: porosities)

Figure 9: Optimized composite: composite plate (left) and microscopic observation (right)

\section{Tables:}

Tab 1: Investigated processing parameters (the reference parameters are in bold)

\begin{tabular}{|c|c|c|c|c|c|c|c|c|}
\hline $\begin{array}{c}\text { Process } \\
\text { parameters }\end{array}$ & $\begin{array}{c}\text { Conditioning } \\
\text { of fibers } \\
\text { (NC - C) }\end{array}$ & $\begin{array}{c}\text { Number } \\
\text { of plies } \\
\text { (NP) }\end{array}$ & $\begin{array}{l}\text { Curing } \\
\text { pressure } \\
\text { (CP) }\end{array}$ & $\begin{array}{c}\text { Curing } \\
\text { temperature } \\
\text { (CT) }\end{array}$ & $\begin{array}{l}\text { Cooling } \\
\text { speed (CS) }\end{array}$ & $\begin{array}{c}\text { Exit plate } \\
\text { temperature } \\
\text { (ET) }\end{array}$ & $\begin{array}{l}\text { Post-curing } \\
\text { temperature } \\
\text { (PCT) }\end{array}$ & $\begin{array}{c}\text { Post-curing } \\
\text { duration }(\Delta t \mathrm{PC})\end{array}$ \\
\hline Nomenclature & NC or C & $\begin{array}{l}12 P \\
20 P\end{array}$ & $\begin{array}{l}1 \text { B (bar) } \\
3 \text { B (bar) } \\
5 \text { B (bar) }\end{array}$ & $\begin{array}{l}60\left({ }^{\circ} \mathrm{C}\right) \\
80\left({ }^{\circ} \mathrm{C}\right)\end{array}$ & $\begin{array}{c}\text { Nat (Natural) } \\
1\left(1^{\circ} \mathrm{C} / \mathrm{min}\right) \\
2\left(2^{\circ} \mathrm{C} / \mathrm{min}\right)\end{array}$ & $\begin{array}{l}20\left({ }^{\circ} \mathrm{C}\right) \\
40\left({ }^{\circ} \mathrm{C}\right) \\
60\left({ }^{\circ} \mathrm{C}\right)\end{array}$ & $\begin{array}{c}\text { X (without) } \\
60\left({ }^{\circ} \mathrm{C}\right) \\
80\left({ }^{\circ} \mathrm{C}\right)\end{array}$ & $\begin{array}{c}\text { X (Without) } \\
1 \text { (h) } \\
2 \text { (h) } \\
4(\mathrm{~h})\end{array}$ \\
\hline \multirow{14}{*}{ Tested values } & \multirow{2}{*}{ NC } & 12 & \multirow{11}{*}{$3 \mathrm{~B}$ (bar) } & \multirow{2}{*}{$80\left({ }^{\circ} \mathrm{C}\right)$} & \multirow{6}{*}{ Nat } & $20\left({ }^{\circ} \mathrm{C}\right)$ & \multirow{3}{*}{$x$} & \multirow{3}{*}{$x$} \\
\hline & & 20 & & & & $40\left({ }^{\circ} \mathrm{C}\right)$ & & \\
\hline & \multirow{12}{*}{$\begin{array}{c}\mathrm{C} \\
\text { (7 days at } \\
23^{\circ} \mathrm{C} \text { and } \\
50 \% \mathrm{RH})\end{array}$} & \multirow{9}{*}{12} & & $60\left({ }^{\circ} \mathrm{C}\right)$ & & \multirow{3}{*}{$60\left({ }^{\circ} \mathrm{C}\right)$} & & \\
\hline & & & & \multirow{11}{*}{$80\left({ }^{\circ} \mathrm{C}\right)$} & & & $60\left({ }^{\circ} \mathrm{C}\right)$ & $1(\mathrm{~h})$ \\
\hline & & & & & & & $80\left({ }^{\circ} \mathrm{C}\right)$ & $1(\mathrm{~h})$ \\
\hline & & & & & & $20\left({ }^{\circ} \mathrm{C}\right)$ & $x$ & $x$ \\
\hline & & & & & \multirow{4}{*}{$2\left({ }^{\circ} \mathrm{C} / \mathrm{min}\right)$} & \multirow{4}{*}{$40\left({ }^{\circ} \mathrm{C}\right)$} & \multirow{3}{*}{$80\left({ }^{\circ} \mathrm{C}\right)$} & $1(\mathrm{~h})$ \\
\hline & & & & & & & & $2(h)$ \\
\hline & & & & & & & & $4(h)$ \\
\hline & & & & & & & \multirow{5}{*}{$x$} & \multirow{5}{*}{$x$} \\
\hline & & & & & $1\left({ }^{\circ} \mathrm{C} / \mathrm{min}\right)$ & $20\left({ }^{\circ} \mathrm{C}\right)$ & & \\
\hline & & \multirow{3}{*}{20} & $1 \mathrm{~B}$ (bar) & & \multirow{3}{*}{ Nat } & \multirow{3}{*}{$40\left({ }^{\circ} \mathrm{C}\right)$} & & \\
\hline & & & $3 \mathrm{~B}$ (bar) & & & & & \\
\hline & & & 5 B (bar) & & & & & \\
\hline
\end{tabular}


Tab 2: Definition of the influence rank depending on the variation of mean values and on the significance value $\mathrm{S}$

\begin{tabular}{|c|c|c|c|}
\hline & $\mathrm{S}>1$ & $1 \geq \mathrm{S} \geq 0.5$ & $0.5>\mathrm{S}$ \\
\hline var. $>15 \%$ & 1 & 3 & $\mathrm{X}$ \\
\hline $10 \%<$ var. $<15 \%$ & 2 & 3 & $\mathrm{X}$ \\
\hline var. $<10 \%$ & $\mathrm{X}$ & $\mathrm{X}$ & $\mathrm{X}$ \\
\hline
\end{tabular}

Tab 3: Influence of process parameters on fabricated laminates microstructural properties, E1, E2 and $\sigma_{\max }($ st dev $=$ standard deviation $)$

\begin{tabular}{|c|c|c|c|c|c|c|c|c|}
\hline \multicolumn{2}{|c|}{ Process step } & Cond. & Pressure & $\begin{array}{c}\text { Curing } \\
\text { temp. }\end{array}$ & $\begin{array}{c}\text { Cooling } \\
\text { speed }\end{array}$ & $\begin{array}{c}\text { Exit } \\
\text { temp. }\end{array}$ & $\begin{array}{c}\text { Post-Curing } \\
\text { temp. }\end{array}$ & $\begin{array}{c}\text { Post-Curing } \\
\text { duration }\end{array}$ \\
\hline \multirow{2}{*}{$\begin{array}{c}\text { Rank of } \\
\text { influence on } \\
\text { mictrostr. }\end{array}$} & $\mathrm{Tg}$ & $\mathrm{X}$ & $\mathrm{X}$ & $\mathrm{X}$ & $\mathrm{X}$ & $\mathrm{X}$ & $\mathrm{X}$ & $\mathrm{X}$ \\
\cline { 2 - 11 } & $\mathrm{Vp}$ & $\mathrm{X}$ & 1 & $\mathrm{X}$ & $\mathrm{X}$ & $\mathrm{X}$ & $\mathrm{X}$ & $\mathrm{X}$ \\
\hline \multirow{2}{*}{$\begin{array}{c}\text { Rank of } \\
\text { influence on } \\
\text { mech. prop. }\end{array}$} & $\mathrm{E} 1$ & 2 & 1 & $\mathrm{X}$ & $\mathrm{X}$ & $\mathrm{X}$ & $\mathrm{X}$ & $\mathrm{X}$ \\
\cline { 2 - 11 } & $\mathrm{E} 2$ & 1 & 1 & $\mathrm{X}$ & $\mathrm{X}$ & 1 & $\mathrm{X}$ & 2 (st dev) \\
\cline { 2 - 11 } & $\mathrm{\sigma}$ & $\mathrm{X}$ & 1 & $\mathrm{X}$ & 2 & 3 & $\mathrm{X}$ & 2 (st dev) \\
\hline
\end{tabular}



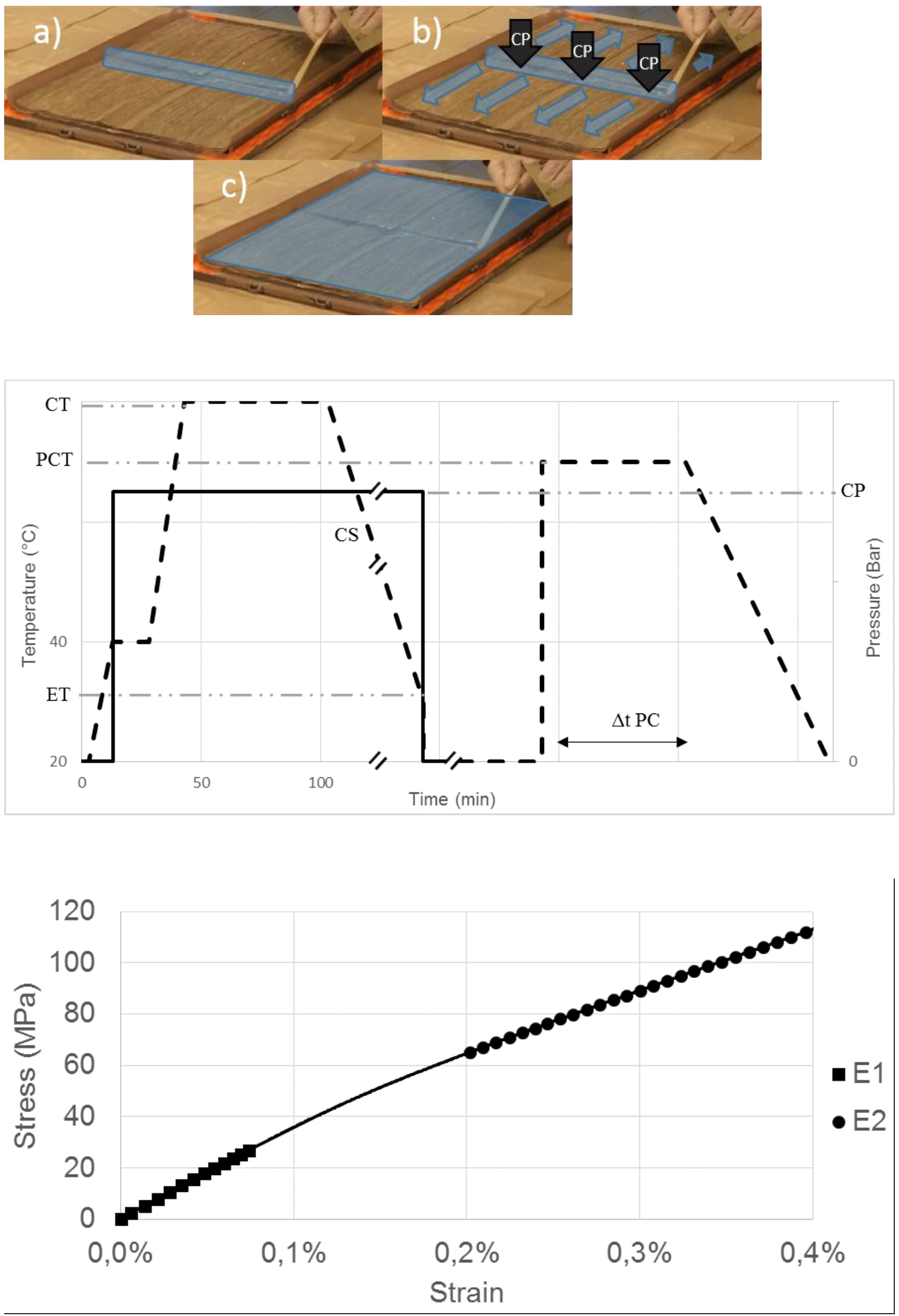

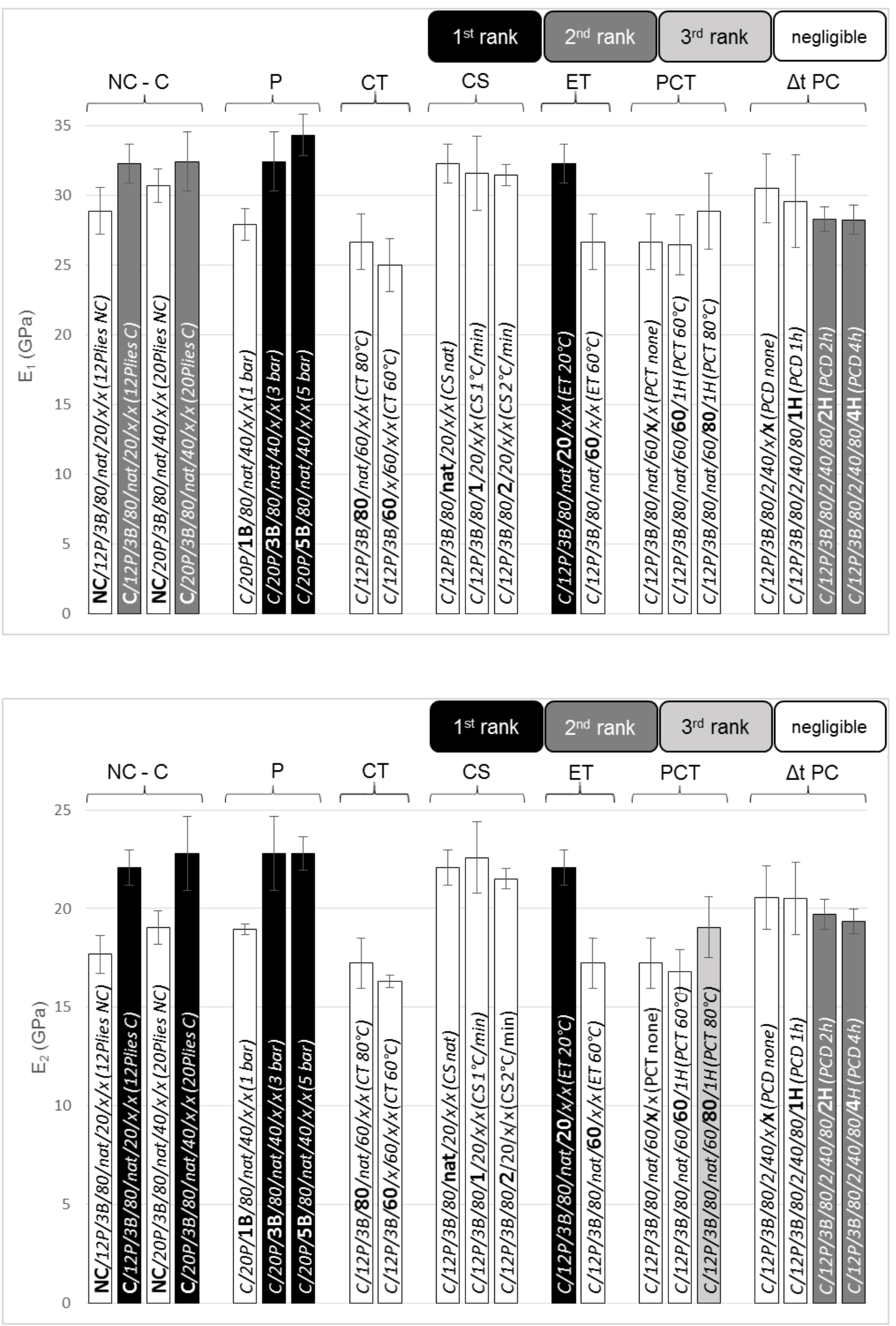


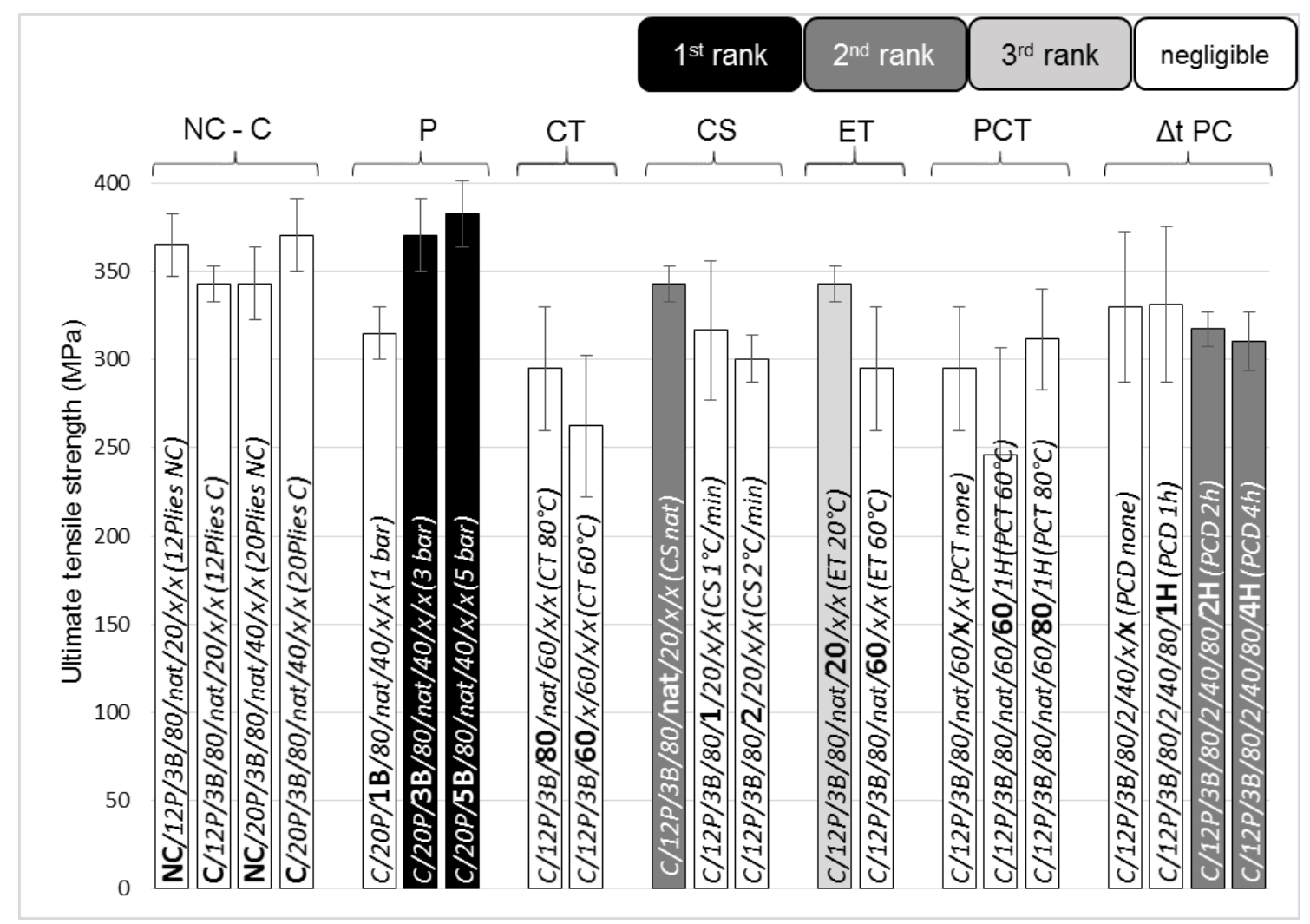




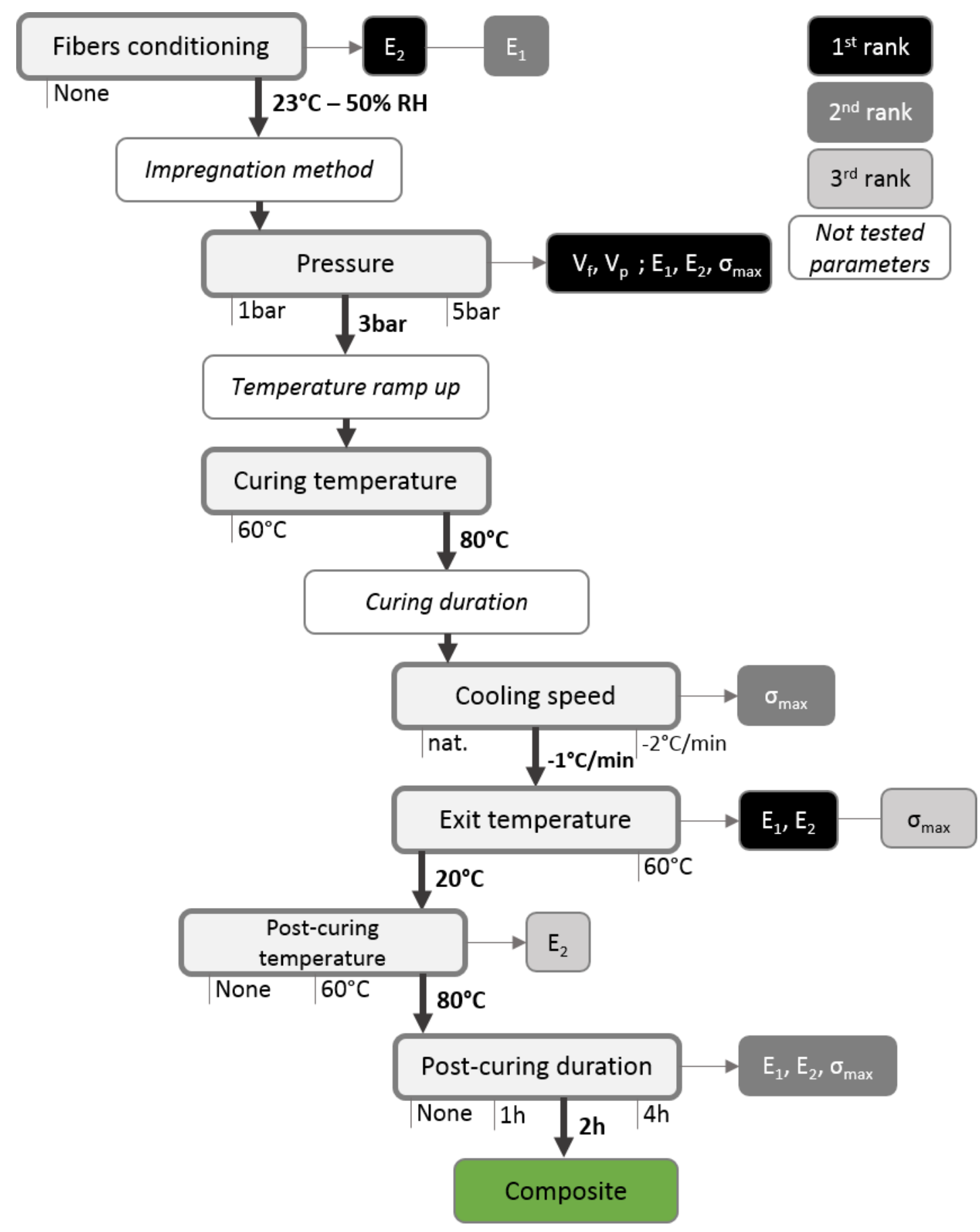



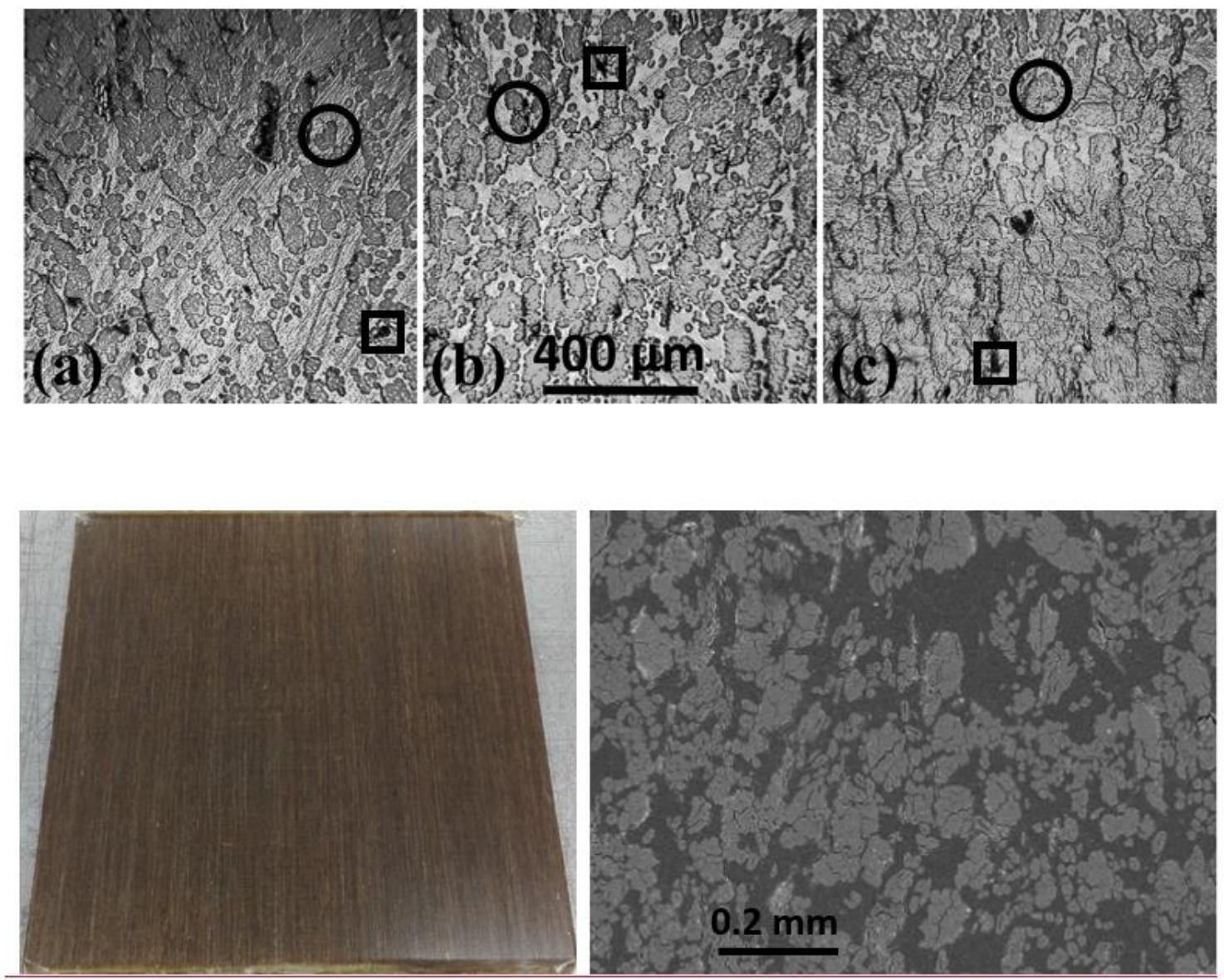